\title{
Repertorio bibliográfico de la biblioteca del padre Burriel
}

\author{
Juan Carlos Galende díaz
}

Pocos son los estudios que existen sobre la figura del escritor y erudito arqueólogo Andrés Marcos Burriel y López ${ }^{1}$. Éste es el motivo que nos ha inducido a dedicarle las próximas líneas, en las que nos centraremos especialmente en la exposición de los libros que componían su biblioteca particular; sin duda, tema del máximo interés para especialistas de diferentes materias.

Antes de analizar este aspecto puntual, creemos que puede ser interesante conocer algunos apuntes biográficos suyos ${ }^{2}$. Andrés Marcos Burriel nació en la localidad conquense de Buenache de Alarcón el día 29 de noviembre del año 1719. Después de una infancia y juventud dedicada a los libros, ingresó en la Compañía de Jesús en 1731. Más tarde cursó estudios de retórica en Cuenca en 1733, de filosofía y teología en Toledo (1734-1739), de teología en Murcia (1739-1740), profesor de gramática en Toledo (en donde fue ordenado sacerdote en 1743), repetidor de filosofía en el Colegio Imperial de Madrid (1745), director supernumerario en el Seminario de Nobles de Madrid (1746) y profesor de filosofía peripatética en el colegio jesuítico de Alcalá de Henares (1747). Perteneciendo ya a la citada orden religiosa, en 1749 fue destinado por sus superiores a las

\footnotetext{
Quizá, recientemente, sea ALFONSO ECHANOVE el autor que más ha profundizado en su figura; suyos son los estudios «Apuntamiento de algunas ideas para fomentar las letras del padre Burriel», Hispania Sacra, xx (1967), págs. 363-437, y «La preparación intelectual del padre Marcos Burriel», Hispania Sacra, xxıv (1971), págs. 45-187.

2 Para elaborar esta breve biografía, además de los citados estudios de A. ECHANOVE, hemos consultado las siguientes obras: J. CONTRERAS, "El padre Burriel», llust. Esp. y Amer., 58 (1914), págs. 295-299 y 311-315; A. DE Góngora, Poligrafos españoles del siglo xvill. El padre Andrés Marcos Burriel, apuntes bio-bioliográficos. Jerez, 1906; P. SÁINZ, el padre Burriel, paleógrafo. Madrid, 1926; y J. SIMÓN, "Un erudito español: el padre Andrés Marcos Burriel», Revista Bibliográfica y Documental, 3,1949 , págs. $5 \cdot 52$.
} 
misiones de América. Por ello, dirigió sus pasos hasta Cádiz, pero estando ya en esta ciudad, recibió el aviso de suspender el embarque y trasladarse a Madrid para ejercer su ministerio, bajo la dirección del padre Rábago, confesor del rey ${ }^{3}$.

Al año siguiente, por solicitud del padre Rábago y del ministro Ensenada, dirigió una comisión, junto con el Dr. Pérez Bayer, encargada de revisar la documentación existente en los archivos toledanos, en especial el de la Iglesia Metropolitana. Veamos la Real Orden remitida en septiembre de 1750 por José de Carvajal y Lancaster, en nombre del rey, a la Santa Iglesia de Toledo, por la que se daba comisión a los anteriormente citados para llevar a cabo la labor encomendada:

«Deseando el Rey eficazmente que logre su debido lustre esta Monarquía en una historia eclesiástica que con regla y método de unidos tan estupendos casos como han pasado en ella; y considerando que en este gran mapa ocupará crecidísimo, ó el mayor lugar esa Santa Iglesia Primada, á la que desea no se le disminuyan sus glorias, ni se le apropie ninguna mal fundada, quando tiene tantas verídicas; ha creído conveniente que se tome la segura instrucción en su archivo por el padre Andrés Marcos Burriel de la Compañía de Jesús, y el Doctor Don Francisco Pérez Bayer, catedrático de lengua hebrea de la Universidad de Salamanca, sujetos ambos dignos de tal asunto.

Desea Su Magestad que el Cabildo contribuya á esta grande obra, facilitándoles que registren sus archivos, y tomen las citas y apuntaciones conducentes. $Y$ si el Cabildo quisiere nombrar uno de sus individuos que les ayude en este digno empleo, será muy del agrado de Su Magestad.

Todo lo espera del zelo del Cabildo, y asi me manda que se lo exprese.

Nuestro Señor guarde a V.S.M. como deseo. Buen Retiro, 17 de septiembre de 1750. Joseph de Carbajal y Lancaster. Señores Deán y canónigos de la Santa Iglesia de Toledo, Primada de las Españas» 4.

Durante este tiempo transcribió más de 2.000 documentos de una importancia capital para la historia civil y eclesiástica posterior a la conquista

3 Este tema es tratado por Andrés Marcos Burriel en la correspondencia que mantiene con su hermano Pedro Andrés, y de la cual podemos encontrar copia en la Biblioteca de la Real Academia de la Historia, signatura $9 / 5921$, folios 14-16. Esta signatura corresponde a volumen conservado en este Centro, establecido por Felipe $V$ en 1713, desde que el 5 de marzo de 1841 fue regalado por el señor Sancha, según podemos leer en el folio $1^{9}$. Se trata de un tomo encuadernado, mediante tapas de cartón, que contiene diversas piezas documentales, todas manuscritas en tamaño folio, referentes a materias dispares: obras de Melchor de Macanaz, pruebas para ser cabailero de la orden de Carlos III, biografías de diferentes personajes, etc. Estas piezas documentales forman una especie de cuadernillos, que se cosen todos juntos - uno detrás de otro-, al lomo interno del libro; es por ello que la numeración de sus folios es seguida, siendo el total de éstos de 184.

4 Biblioteca de la Real Academia de la Historia, signatura 9/5921, folio $13 \mathrm{r}$ y $13 \mathrm{v}$. 
de aquella ciudad por los castellanos ${ }^{5}$. Asimismo, podemos apuntar que no fue sólo ésta la única comisión nombrada para registrar documentos en archivos; Barcelona, Córdoba, Madrid, Cuenca, Valencia, Oviedo, Zaragoza o Gerona son algunos ejemplos de localidades en las que se llevó a efecto esta práctica.

Llevada a cabo esta misión, con la que la historiografía española alcanzó altos niveles - junto a las figuras de Mayáns y el padre Flórez-, Burriel es destinado en 1756 a Toledo como profesor de Teología y en 1760 a la cátedra de casos de moral del Colegio Imperial de Madrid. Después de una fecunda labor, enfermo, regresa a su ciudad natal, en donde falleció el día 19 de junio de 1762. Vista esta breve noticia biográfica, citaremos la principal producción bibliográfica de este autor, parte de la cual estuvo basada en las investigaciones realizadas de los documentos examinados durante su estancia toledana:

- Memorias para la vida del Santo Rey Fernando III, que dedicó al monarca Fernando VI -del que había sido confesor-, y que fueron publicadas en 1800 por Miguel Manuel Rodríguez en la imprenta de la viuda de D. Joaquín Ibarra en Madrid ${ }^{6}$.

- Una copia de la Liturgia Mozárabe, que comprendía 11 tomos del Misal Mixto, llamado «Mozárabe».

- Copia del célebre Breviario del Cardenal Jiménez, del que sólo se imprimieron unos 35 ejemplares en Toledo.

- Noticia de la California y de su conquista espiritual y temporal (3 tomos, imprenta de la viuda de Manuel Fernández, Madrid, 1757). Esta obra está basada en las Memorias publicadas en México en 1739 por el padre Miguel Venegas. Al parecer, la labor de Andrés Burriel fue la de compilar datos ${ }^{7}$. Una vez publicada, rápidamente fue traducida a otros

5 Bajo el epígrafe “Copia de cartas de Ministros de Estado y confesores del Rey al padre Burriel, y de éste a aquéllos", podemos encontrar diferentes detalles relativos a la comisión de registrar los archivos de Toledo. Entre ellos podemos citar a personalidades tales como el padre Flórez, agustín Pablo de hordeñana, Francisco de Rábago, juan de Chindurza, el duque de HuÉsCAr, RICARDO WALl, el duque de Alba, el Inquisidor General o Gregorio Mayáns. Biblioteca de la Real Academia de la Historia, signatura 9/5921, folios $12 r-53 r$.

6 Posteriormente han sido reeditadas en Barcelona el año 1974.

7 Sobre este tema es muy importante un legajo conservado en la Biblioteca de la Real Academia de la Historia con la signatura 9/2282. En él se conserva diferente documentación manuscrita, en papel, sobre California y su conquista. Así podemos comprobar que en él se encierran piezas documentales tan interesantes como los encargos dirigidos por Andrés Marcos Burriel al padre Francisco Ceballos - procurador de la provincia de Nueva España-, el memorial que el padre Rodero envió al Rey sobre California o el manuscrito del propio padre Miguel Venegas. 
idiomas; tenemos noticias de que en Londres se publicó en 1759 y en Paris en 1767.

- Informe de la ciudad de Toledo para el Consejo de Castilla sobre la igualación de pesas y medidas (1758).

- Prefacio de la verdadera colección de cánones de la lglesia española por San Isidoro (1752). Fue publicado en latín por Carlos Laserna en el año 1800.

- Prólogo de los Viajes al Ecuador, de Jorge Juan y Antonio Ulloa.

- Paleografía Española, del padre Esteban Terreros y Pando (1755-58) ${ }^{8}$.

- Gran número de memorias, cartas y discursos, tenidos en gran aprecio por los eruditos. De este modo es muy interesante su correspondencia

También podemos encontrar en esta pieza archivistica diferentes noticias sobre nuevos descubrimientos y correspondencia original del padre Burriel con Juan Antonio Baltasar, Diego Davin o Miguel del Barco.

${ }_{8}$ El propio Esteban Terreros reconoce, en las hojas finales de su obra, la participación de Burriel en la elaboración de la misma. Es más, diferentes autores aseguran que la mayor parte de las ideas e ilustraciones aportadas en el libro son del erudito conquense. Sírvanos de ejemplo de esta teoría la opinión de Sáinz Rodríguez, quien en su obra citada con anterioridad, literalmente expone en las páginas 26 y 27: «es indudable que la Paleografía propiamente dicha es de Burriel, a cuyos deseos se sometió Terreros, ocultando el nombre del verdadero autor, aunque no pudo menos de citarle al tinal de su obra. Creo también que Terreros trabajó en ella, sobre todo en la parte filológica, en que era más entendido, y añadió algo en la segunda edición». Lo que sí es cierto, problemas de paternidad aparte, es que en 1755 publicó Esteban Terreros una Paleografía Española incorporada a la traducción de la «Enciclopedia» de Pluche, titulada Le Spectacle de la Nature, en sustitución del tomo XIII de la Paleografia Francesa; más tarde, con bastantes adiciones y correciones, fue de nuevo editada independientemente en Madrid por el conocido impresor Joaquín Ibarra el año 1758, estando en esta ocasión dedicada a la reina Bárbara de Braganza. Consta de 160 páginas y de diferentes ilustraciones sobre modelos de escrituras empleados hasta ese momento. Entre los diferentes ejemplares conservados en la actualidad, la Biblioteca Nacional atesora uno (signatura Mss. Imp./3904); en él, se puede comprobar cómo el autor que figura en la portada es Esteban Terreros («Paleografía española, que contiene todos los modos conocidos, que a habido de escribir en España, desde su principio, y fundación, hasta el presente, á fin de facilitar el registro de los Archivos, y lectura de los manuscritos, y pertenencias de cada particular; juntamente con una historia sucinta del idioma común de Castilla, y demás lenguas, ó dialectos, que se conocen como propios en estos Reynos. Por el P. Estevan de Terreros y Pando, Maestro de Matemáticas en el Colegio Imperial de la Compañia de Jesús de esta Corte»), quien en el epilogo agradece el padre Burriel su colaboración, en especial por haberie remitido las 18 láminas que inserta en el volumen, las cuales han sido confeccionadas por Francisco Javier de Santiago y Palomares, oficial de la Contaduría Principal de Rentas Provinciales de Madrid; es más, literalmente añade: «De la fidelidad de los dibujos no se puede dudar, porque la destreza de dicho Don Francisco Xavier en esta materia es sin igual, y dicho P. Burriel los cotejó prolixamente con los originales"; asimismo, en la citada portada, y entre paréntesis, aparece una nota manuscrita con letra humanística en la que se puede leer que el autor del libro es Andrés Marcos Burriel ("Fue su verdadero autor el eruditisimo Padre Andrés Marcos Burriel»). Sin embargo, en la fe de erratas, elaborada por el doctor don Manuel González Ollero, corrector general por Su Majestad, en Madrid el día 25 de enero de 1758 , certifica que el original es de Terreros y Pando. 
epistolar, en especial desde 1744 a 1758 , entre la que destaca las Cartas eruditas y críticas, y alguna misiva dirigida a personalidades tales como D. Juan de Amaya o a D. Carlos de Simón Pontero, sobre un proyecto para hacer navegables los ríos Tajo, Guadiela, Manzanares y Jarama ${ }^{9}$.

Expuesto lo anterior, pasaremos a continuación a detallar los manuscritos y libros impresos que se hallaron en el aposento madrileño de este Maestro de Prima de Teología en el colegio de Toledo. Para ello, vamos a transcribir dos documentos, en los que se nos ofrece una relación detallada de estos ejemplares ${ }^{10}$.

El primero de ellos es un inventario, realizado por Real Orden de 24 de junio de 1762 —comunicada por el Marqués de Campo Villar-, que comenzó a efectuarse el día siguiente y se terminó el 8 de julio. Durante su confección estuvieron presentes el Rector del Colegio Imperial de Madrid, Reverendísimo padre Diego de Rivera ( $y$ en sus ausencias el padre ministro del mismo Colegio), D. Francisco Morán, D. José de Castro y D. Justo del Cerro (escribanos de la Real Biblioteca, enviados por Juan de Santander, Bibliotecario Mayor). Este inventario, que lleva por título $D e$ los manuscritos pertenecientes a Su Majestad que se hallaban en el aposento del Reverendo padre Andrés Burriel, fue compuesto en Madrid por el citado Juan de Santander el día 9 de julio de 1762. En él se nos dice que una vez concluido el inventario, fueron trasladados los 120 manuscritos que lo conformaron a la Biblioteca Real. Asimismo, se especifica que todos los libros y legajos en que no se expresa el tamaño son en folio. Detallemos la relación:

«- Numero 1. Poesias en lengua gallega ó portuguesa antigua de Don Alonso 10, llamado el Sabio, Rey de Castilla y de Leon, copiadas de un tomo en pergamino de la Libreria de la Santa Yglesia de Toledo corregido al parecer de mano del mismo Rey. $1^{\circ}$ tomo enquadernado en pasta con una lamina en dibujo al principo en que está Nuestra Señora y dicho Rey en ademan de dirigir a S.M. estas poesias.

\footnotetext{
9 Muchas de estas cartas fueron publicadas en la Revista de Archivos por el Dr. D. EMILIO Gigas el año 1924.

10 Esta pieza documental consistente en un cuadernillo manuscrito, tamaño folio ( $310 \mathrm{~mm}$. $\mathrm{x}$ $215 \mathrm{~mm}$.), conservado en buen estado en la Biblioteca de la Real Academia de la Historia, con la signatura 9/7165; está escrito opistógrafamente con tinta de color sepia, y configurado por 10 bifolios y un último folio, conformando un total de 21 hojas. El legajo, en general, está compuesto por 16 piezas documentales, en papel, de variada temática (himno en honor de María Cristina, documentación sobre Las Cantigas, piezas literarias, copia de los privilegios concedidos a Laredo hasta 1783, marcas de papel, estudios sobre localidades españolas, el estado de la deuda del Real Erario de Nueva España hasta fin de 1815, etc.), siendo nuestro documento el expediente número 2 de esta colección.
} 
- Numero 2. Libro de los 12 trabajos de Hercules compuesto por Don Henrrique de Aragon, Marques de Villena, copiado de un manuscrito antiguo en Toledo año de 1755. 1 tomo.

- Numero 3. La Gaya de Segovia ó Selva de consonantes y asonantes castellanos, escrita por N. Segovia, dedicada por el autor a Don Alonso Carrillo, Arzobispo de Toledo, copiada año de 1754 de un codigo antiguo de la Libreria de la Santa Yglesia de Toledo por el Padre Andres Burriel de la Compañia de Jesús. $1^{\circ}$ tomo és copia incompleta.

- Numero 4. Un tomo en $4^{\circ}$ enquadernado en pergamino de las obras de Juan Ruiz, Arcipreste de Yta, poeta del siglo 14, copiado del exemplar de la Santa Yglesia de Toledo año 1753.

- Numero 5. Commentaria in 8 Libros Phisicorum Aristotelis, et in 3 Libros eiusdem de Anima: Per V.CL Joannem de Vergara, canonicum toletanum \& excripta ex tomo quodam authografo in Bibliotheca Toletanae Ecclesia Hispaniarum Primatis, adservato a P. Andrea Burriel, societatis lesu. $1^{\circ}$ tomo.

- Numero 6. Fragmentos de dos obras de todas las partes de la Agricultura y cria de animales compuestos al parecer por autor mahometano español en lenguage antiguo castellano ó bien traducidas del arabigo, copiadas año 1753 por el padre Andres Burriel de un tomo manuscrito en papel y letra del siglo 14, que se guarda en la libreria de la Santa Yglesia de Toledo; tiene al principio la muestra del caracter en que está escrito el original de ésta copia. 1 tomo.

- Numero 7. Un legajo con cubierta de pergamino que contiene 3 quadernos: el $1^{\circ}$ con 5 extractos de obras de la libreria de San Juan de los Reyes, el $2^{\circ}$ de la Biblia gotica de Toledo y el $3^{\circ}$ De constitutionibus et consuetudinibus ecclesiae Toletanae.

- Numero 8. Sanbsonis Abbatis cuiusdam monasterii cordubensis adversus Hostigesium Malacitanum Episcopum. Apologetici libri, qui stant duo, ex veteri gotico membranaceo, codice Santae ecclesiae Toletanae, erudi anno 1752 . $1^{\circ}$ tomo que tiene dentro en un pliego suelto la muestra del caracter de dicho codigo.

- Numero 9. Un legajo sin cubierta que contiene 3 copias de opusculos de San Valerio, el $1^{\circ}$ de Laude Egeriae; una carta de Evancio arcediano de Toledo, y el yndice de lo que contiene el tomo gotico del cajon 15, numero 5, del archivo de Toledo, en que están dichas obras de san Valeio, san Fructuoso y otras.

- Numero 10. Un legajo sin enquadernar que contiene 6 copias de varios opusculos de san Martin Dumiense y una carta de san Fructuoso al Rey Recesvintho.

- Numero 11. Un legajo sin cubierta que contiene 14 copias, és a saber: noticia de la división de Fajon, obispo de Zaragoza con la descripcion del codice en que se halla y su cotejo; y la de la invencion de los morales de san Gregorio; opusculo de san Ysidoro, intitulado Bibliotheca Ysidori; extracto de algunos nombres de ciudades sacado del codice de su obra de las Etimologias; cotejos del cronicon e Historia de los godos del mismo santo; 
versos penitenciales de Verecundo, alias Vergundo, obispo africano; cotejo de algunas obras de san Eugenio, Cipriano Cordoves, Alvaro, y Alon gramatico.

- Numero 12. Un legajo sin cubierta que contiene 2 quadernos: el $1^{\circ}$ de las obras de san Yldefonso, corona Beatae Mariae Virginis y de su oficio en los Breviarios de España, y el $2^{\circ}, 2$ cartas de san Hugo abad de Cluny, a don Bernardo arzobispo de Toledo y de Eugenio a Protasio obispo, y un privilegio del Rey Chindasvinto al monasterio de san Justo y Pastor de Alcalá, fundado por san Fructuoso.

- Numero 13. Un legajo sin cubierta que contiene 3 quadernos: el 10 con 16 piezas del cotejo de las obras de san Ysidoro, el $2^{\circ}$ quatro sobre lo mismo y el $3^{\circ}$, tratado de San Leandro de Virginitatae ad Florentinam sororem. Copia moderna.

- Numero 14. Misale Muzarabicum misas omnes, tan tempore, quam de sanctis per totum annum circulum continens é vetustissimocodice Ecclesiae Toletanae, descriptum aliquod notis in marginibus positis a $P$. Burriel anno 1753.

- Numero 15. Codex Muzarabicus tam oficia quam misas de tempore á Pascate usque ad Adventum Domini continens é vetustisimo exemplari Bibliothecae Almae Ecclesiae Toletanae, descriptum cum aliquod notis in magnibus positis a P. Andrea Marco Burriel anno 1753.

- Numero 16. Codex Muzarabicus continens aficia et misas de tempore á Pascate usque ad Pentecostem et de Sanctis usque ad diem sanctae Justi et Pastoris é vetustisimo exemplari Bibliothecae Almae Ecclesiae Toletanae Hispaniarum Primatis, literis goticis exarato descriptus cum aliquod notis in inarginibus positis a P. Andrea Marco Burriel anno 1753.

- Numero 17. Codex Misarum S. Yldefonsi in quo prius tractatus eiusdem de perpetua virginitate Beatae Mariae in misas septem divisus est deinde extat misa in die Anunciationis seu incarnationis Domini cuius pars est sermo eiusdem S. Yldefonsi; postea Misa in Asumptione B. Mariae; oficia tandem et Misae á die Nativitate Domini usque ad diem Epiphaniae seu aparitionis Domini é vetustisimo exemplari Bibliothecae Almae Ecclesiae Toletanae Hispaniarum Primatis literis goticis exarato descriptus et aliquod notis in marginibus positis illustratus á P. Andrea Marco Burriel anno 1753.

- Numero 18. Codex Muzarabicus continens Psalterium integrum libris 5, distinctum cum Antiphonis notisque musicalibus uniuscuiusque Psalmi propis é vetustisimo exemplari literis goticis exarato et in Bibliotheca Almae Ecclesiae Toletanae Hispaniarum Primatis á servato descriptus anno 1756.

- Numero 19. Codex Muzarabicus continens tum officia tum misas de quadragesima é vetustisimo exemplari literis goticis exarato descriptus cum notis P. Andrea Marco Burriel anno 1753.

- Numero 20. Codex Muzarabicus in quo continentur officium totius quadragesimae excepta mayori hebdomada é vetusto exemplari cun aliquod notis $P$. Burriel descriptus anno 1752.

- Numero 21. Codex Muzarabicus in quo continentur óficia de S. Martino, S. Aemiliano et de Asumptione B. Mariae Virginis e vetustisimo men- 
branaceo exemplari Bibliothecae Almae Ecclesiae Toletanae literis goticis exarato additis etiam notis musicalibus goticis quotquot in eo reperiuntur, descriptus á P. Andrea Marco Burriel anno 1752.

- Numero 22. Codex Muzarabicus continens Hymnos per totum anni circulum é vetustisimo exemplari Bibliothecae Almae Ecclesiae Toletanae Hispaniarum Primatis literis goticis exarato descriptus anno 1756.

- Numero 23. Codex Muzarabicus continens cantica in horis canonicis usitata é vetusto exemplari; Pluteo $3^{\circ}, \mathrm{m}^{\circ} 1^{\circ}$ cum aliquod notis in marginibus a P. Burriel anno 1754.

- Numero 24. Homiliarium Muzarabicum é vetustisimo membranaceo exemplari Bibliothecae Almae Toletanae Ecclesiae Hispaniarrum Primatis literis goticis exarato desdriptum á P. Andrea Marco Burriel anno 1753.

- Numero 25. Un legajo en folio sin cubierta que contiene 90 copias del Santoral Muzarabe y al principio un quaderno impreso en $4^{\circ}$ intitulado Breve suma y relacion del modo de rezo y misa del oficio santo gotico muzarabe en Toledo año 1603.

- Numero 26. Un legajo sin cubierta que contiene 3 quadernos és á saber: $1^{\circ}$, Razon del pleyto de los muzarabes de Toledo con los capellanes nuevos de dicha ciudad; 2 , Tratado historico chronologico de los privilegios de los muzarabes; $3^{\circ}$, confirmación de éstos privilegios por el señor Carlos $2^{\circ}$.

- Numero 27. Un legajo sin cubierta que contiene 60 copias de kalendarios sacados de diferentes breviarios, papeles y privilegios muzarabes de Toledo.

- Numero 28. Un legajo sin cubierta que contiene 3 quadernos y pliegos és á saber: quaderno $1^{\circ}$, Privilegios de los muzarabes y castellanos; $2^{\circ}$, Ordenamiento de Sevilla; $3^{\circ}$, Noticia (sic: noticia) de los Misales de Toledo.

- Numero 29. Un legajo sin cubierta que contiene 11 quadernos y pliegos, és á saber: quaderno $1^{\circ}$, tabla del Dr. Francisco de Pisa sobre el oficio muzarabe copiada de la misma que el imprimió; $2^{\circ}$, noticia de la traduccion castellana de las Homilias de San Gregorio; $3^{\circ}$, Yndex codicis smaragdini; $4^{\circ}$ Misale mixtum; $t^{\circ}$, Breviarium secundum regulas $S$. Ysidori; $6^{\circ}$, Officium et misa in die S. Justae et Rufinae; $7^{\circ}$, Index codicis Pasionarii; $8^{\circ}$, Lectionarios maximos; $9^{\circ}$, Index Libri comitis á Smaragdo Abbate; 10, Misal antiguo de Sahagun; 11, Lectiones aliquot ex diversis lectionariis; los restantes son pliegos.

- Numero 30. Martirologium Acefalum Usuardi saeculo 11 vel 12 literis gallicis conscriptum, quo antiquum monasterium canonicorum regularum $\mathrm{S}$. Vicentti de la Sierra toletanae diocesis, olim osum est; é codice Bibliotheca Almae Ecclesiae Toletanae Hispaniarum Primatis desciptum anno 1752.

- Numero 31. Martirologium Usuardi ad usum Sanctae Ecclesiae Toletanae Hispaniarum Primatis ex antiquo codice Bibliothecae eiusdem Ecclesiae erutum cum aliquot notis in marginibus positis a $P$. Andrea Burriel anno 1754.

- Numero 32. Un legajo con cubierta de pergamino que contiene un quaderno intitulado Acta originalia Toletani Concilii, celebrati sub Cardinalis Quiroga, Archiepiscopus Toletanus anno 1582 et 1583, copiado en 460 folios del original que se guarda en Toledo y a su continuacion las variantes entre 
el original y el ympreso por el Cardenal de Aguirre, sacadas por el Dr. D. Francisco Bayer y el P. Andres Burriel y asimismo al principio del orden con que sentaron los prelados que asistieron á él con sus suscripciones en dos vitelas que están al principio.

- Numero 33. Un legajo con cubierta de pergamino que contiene 1 quaderno de coleccion de varias cartas y documentos pertenecientes asi al expresado concilio Provincial como al antecedente tambien de Toledo del año 1566.

- Numero 34. Libellus cardinalis Petri Bertrandi de distintione jurisdictionum spiritualis et temporalis et carum connexione ad invicem, $1^{\circ}$ tomo copiado de la Santa Yglesia de Toledo.

- Numero 35. Actas de la Junta de theologos, celebrada en Alcalá, y presidida con autoridad de Sixto $4^{\circ}$ por Don Alonso Carrillo, arzobispo de Toledo, contra los errores del maestro Pedro Martinez de Osma, canonigo de la Yglesia de Cordova, copiadas de un manuscrito antiguo de la tibreria de Don Garcia de Loaysa; añadense cun compendio latino de las mismas actas escritos por Pedro de Ponte copiado del original que se guarda en el Archivo secreto de la Yglesia de Toledo y un tratado castellano del Maestro Fr. Juan Lopez, contra otro del mismo Maestro Pedro de Osma, copiado de un tomo antiguo de la libreria de dicha Santa Yglesia.

- Numero 36. Monumenta Elipandiana, sive colectio Monumentorum quae ad Elipandum archiepiscopum Toleti et Felicem episcopum Urgelitani, eorum quae errores de Christi ad optione pertinent, 1 tomo.

- Numero 37. Planeta, opus nempé septem libris distintum in quo de Christo Beatae Virginis Maria Archangelo Michaele de Anima, atque de pace tractatur á Didaco de Campos clerigo, regis Castellae cancellario, ex authografo asservato in Bibliotheca Sanctae Ecclesiae Toletanae erutum anno 1752.

- Numero 38. Historia de España escrita en latin por Don Rodrigo Ximenez, Arzobispo de Toledo, y traducida en castellano antiguo con una nomina sacada año 1752 de un manuscrito antiguo en pergamino en forma de $4^{\circ}$ que se guarda en la librearia de la Santa Yglesia de Toledo.

- Numero 39. Archiepiscoporum Toletanorum vitae Alvaro Gometio Toletano autore, 1 volumen copiado de la Santa Yglesia de Toledo.

- Numero 40. Vida y sucesos prosperos y adversos de Don Fray Bartholomé de Carranza y Miranda, Arzobispo de Toledo, Primado de las Españas, Chanciller mayor de Castilla, por el Dr. Salazar de Mendozacanonigo penitenciario de la mui Santa Yglesia de Toledo; 1 tomo copiado por el Dr. D. Francisco Perez Bayer del que conserva aquella Santa Yglesia.

- Numero 41. Monarquia de España ó deduccion historica y juridica de los derechos del Rey Catholico á todos los estádos que poseia año 1622 con descripcion y noticia de los mas singular de cada uno. Por el Doctor Pedro Salazar de Mendoza canonigo penitenciario de la Santa Yglesia de Toledo, primada de las Españas, copiada para publicarla por el P. Andres Burriel de la Compañia de Jesus, 3 tomos. 
- Numero 42. Historia compostelana é codice Bibliothecae Almae Ecclesiae Toletanae á R.P. Andrea Burriel anno 1753 descripta, 1 tomo.

- Numero 43. Un legajo cubierto de pergamino que contiene 3 quadernos de bulas y privilegios de las ordenes militares de Calatrava, Santiago y san Juan, ynformaciones, bulas y otros papeles sobre la de templarios y diferentes cartas de reyes é infantes de Castilla, papas, arzobispos y otros, y son 55 copias.

- Numero 44 . Un legajo sin cubierta que contine 2 quadernos: el $1^{\circ}$, extracto de acuerdos de la real junta del Toyson y el $2^{\circ}$, algunos papeles pertenecientes á élla.

- Numero 45. Un legajo sin enquadernar que contiene 71 escudos illuminados de la orden de la Vanda y tres borradores de varios escudos hechos de pluma.

- Numero 46. Historia de la Universidad de Salamanca escrita por el Maestro Pedro Chacon copiada del exemplar que tiene el Dean de Toledo Don Juan Antonio de las Ynfantas por el Dr. Don Francisco Perez Bayer.

- Numero 47. Fragmento del libro intitulado Septenario, escrito por Don Alonso 10, Rey de Castilla y de Leon llamado por excelencia el Sabio; el qual és una introduccion á la obra de las 7 Partidas, sacóse de un tomo manuscrito en papel antiguo y letra coetanea al Rey su autor que se guarda en la libreria de la Santa Yglesia de Toledo y se cotejó ésta copia con su original año de 1752, 1 tomo.

- Numero 48. Un legajo sin enquadernar con dos quadernos y 9 copias: el $1^{o}$ con 4 sobre leyes de partidas $1^{\underline{a}}$ y $2^{a}$, apuntamientos de los codices de éllas en el Archivo de Toledo y prologo de Montalbo; $3^{\mathrm{a}}$ y $4^{\mathrm{a}}$, la Ley de la jugada de Toledo y otra de Sevilla sobre pesos y medidas; el $2^{\circ}$ con 5 quadernos: $1^{\circ}$, de apuntamientos de privilegios; $2^{\circ}$, Bula de Clemente $5^{\circ} ; 3^{\circ}$, $4^{\circ}, 5^{\circ}$, varias concordias.

- Numero 49. Fuero Juzgo, ó codigo de las lyes qu elos Reyes Godos promulgáron en España, traducido del original latino al lenguage castellano antiguo por mandado del Santo Rey Don Fernando $3^{\circ}$, copiado de un exemplar autentico del Archivo de la ciudad de Murcia y de otros 3 manuscritos antiquisimos de la libreria de la Santa Yglesia de Toledo ajustado al original latino, con notas del P. Andres Marcos Burriel de la Compañía de Jesus año 1755.

- Numero 50. Un legajo con cartones sueltos que contiene 3 quadernos és á saber: el $1^{\circ}$ de adiciones al Fuero Juzgo, cotejos y apuntamientos sobre las leyes de las 12 tablas y su origen; una pragmatica y 2 decretos sobre tercias y una concordia entre el arzobispo Don Rodrigo y los judios sobre decimas.

- Numero 51. Fuero antiguo de la ciudad de Plasencia dado por Don Alonso $8^{\circ}$, añadidas algunas leyes por Don Sancho 4을 copiado de un quaderno antiguo de pergamino que se guarda en el Archivo de la misma ciudad, año 1754.

- Numero 52. Un legajo sin enquadernar que contiene los fuéros de Alarcon y empieza desde el titulo $1^{\circ}$ que dice Titulo de la franqueza de 
Alarcon y acaba con el titulo 240 que dice: titulo del Portazgo; despues se sigue el yndice en 7 pliegos y no está concluido porque solo llega al titulo de las quintas que es el 233 .

- Numero 53, Un legajo sin cubiertas que contiene 2 quadernos: el 10, noticias del ordenamiento de alcala, de el de Najera, de las leyes de Castilla que llaman Doctrinal de caballeros é hijosdalgo, sacadas de diferentes codices que los comprenden y se conservan en la libreria de la santa Yglesia de Toledo; y el 2º 39 copias de privilegios de los señores reyes Don Alonso el Emperador y Don Fernando.

- Numero 54. Un legajo sin cubierta que contiene quatro quadernos con 15 copias á saber: $1^{\circ}$ quaderno, Fuero antiguo de Escalona, $2^{\circ}$ y $3^{\circ}$, Fueros y ordenanzas de Toledo y $4^{\circ}$, privilegio de Don Alonso $8^{\circ}$ emperador, á la villa de Santa Olalla.

- Numero 55. Un legajo sin cubierta que contiene 4 quadernos con 15 copias, á saber: $1^{\circ}$ quaderno, Fuero antiguo de Escalona; $2^{\circ}$ y $3^{\circ}$, fueros y ordenanzas de Toledo; y $4^{\circ}$, privilegio de don Alonso $8^{\circ}$ emperador á la villa de Santa Olalla.

- Numero 56. Un legajo con cubierta de pergamino que contiene 5 quadernos: el 1ํㅡㄹ un privilegio del Rey don Enrrique 1a los de las aldeas de Toledo que mantubieron caballo y armas; el $2^{\circ}, 15$ copias de instrumentos del rey Don Alonso 10; el $3^{\circ}, 17$ de el de Don Alonso el 11; el $4^{\circ}$, de ordenamiento de Alcalá éra 1386 con la rueda del privilegio y muestras del caracter por Palomares; y el 5º, pragmatica confirmatoria del dicho ordenamiento.

- Numero 57. Un legajo con cubierta de pergamino que contiene 3 quadernos: el $i^{\circ}$, ordenamiento que hizo el Rey Don Alonso en las cortes de Leon que és el Fuero de los Fijosdalgo; el $2^{\circ}$, de las Behetrias de Castilla puesto en nuevo orden por Don Pedro Justiciero, año 1356.

- Numero 58. Un legajo sin enquadernar que contiene 36 copias de privilegios y provisiones, cedulas, pragmaticas y otros instrumentos pertenecientes al reynado de los señores Reyes Catholicos, sacadas del Archivo de la ciudad de Toledo, y otros.

- Numero 59. Un legajo sin cubierta que contiene 2 quadernos: el $1^{\circ}$, con 49 copias de cartas, cedulas, provisiones y pragmaticas de los señores Reyes Catholicos Don Phelipe 1․, Doña Juana y Carlos $5^{\circ}$; y el $2^{\circ}$, declaracion del Dr. Zumel y otros letrados sobre las alcabalas.

- Numero 60. Un legajo sin cubierta que contiene 11 cuadernos de cortes celebradas en Valladolid en los años 1523, 1537, 1542 y 1544, en Toledo el de 1525, 1538 y 1539, en Madrid el de 1528, 1535 y 1551, y un tratado de paces de Clemente $7^{\circ}$ y el Emperador Carlos $5^{\circ}$ del año de 1529.

- Numero 61. Un legajo con cubierta de pergamino que contiene 28 copias de pragmaticas, ordenanzas, cortes y papeles del señor rey Don Juan el $2^{\circ}$.

- Numero 62. Otro legajo cubierto de pergamino que contiene $63 \mathrm{co}$ pias de pragmaticas, cedulas, cortes, ordenamientos y cartas del mismo rey don Juan el $2^{\circ}$ de Castilla. 
- Numero 63. Un legajo con cubierta de pergamino con cinco quadernos: el $1^{\circ}$ que contiene 3 copias de cedulas, cortes é instrumentos del tiempo de Don Pedro el $1^{\circ} ;$ el 2ª, 19 de lo mismo de Don Enrrique $2^{\circ} ;$ el $3^{\circ}, 21$ de

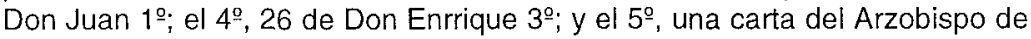
Toledo Don Pedro Thenorio sobre la contribucion del cavildo de su Yglesia para hacer los muros de dicha ciudad.

- Numero 64. Un legajo que contiene 5 quadernos: el $1^{\circ}$ y $2^{\circ}$, de cortes y ordenamientos pertenecientes al reynado de Don Enrrique $2^{\circ}$ y $3^{\circ}$; el $3^{\circ}$, de

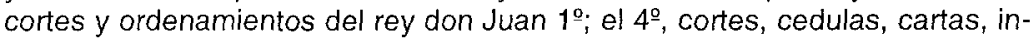
dultos y juramento del señorio de Vizcaya pertenecientes al rey Don Pedro; y el 50, cortes, peticiones y ordenamientos tocantes al reynado de Don Alonso 11, y conciertos hechos en Palazuelos entre la reyna Doña Maria y el ynfante Don Juan Manuel sobre su tutoria.

- Numero 65. Un legajo que contiene 4 quadernos: el 1ํ, cortes, tratados, confederaciones, privilegios y cartas, pertenecientes al reynado de Don Fernando $4^{\circ}$ (el $3^{\circ}$ fueros); el $2^{\circ}$, cortes, confederaciones, paces, cartas, contratos patrimoniales del reynado de Don Sancho $4^{\circ}$; el $3^{\circ}$, fueros de Caceres, por el rey Don Alonso confirmados por el rey Don Fernando $3^{\circ}$; y el $4^{\circ}$, concordia de Don Sancho 3o con Don Fernando de Leon su hermano con motivo de la muerte de Don Alonso $7^{\mathrm{a}}$ el Emperador, su padre.

- Numero 66. Un legajo que contiene 2 quadernos: el 1², Fueros de Sobrarbe y el $2^{\circ}$, Fuero antiguo de Castilla.

- Numero 67. Un legajo que contiene 3 quadernos ó copias de tiempo del rey Don Juan $2^{\circ}$, és á saber: el $1^{\circ}$, Cortes de Valladolid año de 1451 ; el $2^{\circ}$, ordenamiento de leyes de Valladolid; y el $3^{\circ}$, capitulos de concordia otorgados por el Rey Don Juan $2^{\circ}$ y el Principe Don Enrrique su hijo que están en 64 articulos.

- Numero 68. Un legajo que contiene 5 quadernos ó copias del tiempo del rey Don Juan $2^{\circ}$, és á saber: el $1^{\circ}$, ordenamiento de Don Juan $2^{\circ}$ en las cortes de Valladolis; el ${ }^{2}$, quadernos de peticiones de los procuradores de las cortes de Bonilla y Valladolid; el $3^{\circ}$, pragmatica sobre las personas de á pie que devia tener cada una de las personas de la corte; el $4^{\circ}$, quaderno de peticiones de los procuradores de Palenzuela; y el $5^{\circ}$, ratificacion hecha por Don Alonso, Rey de Aragon, y el Ynfante Don Pedro, su hermano.

- Numero 69. Un legajo que contiene 5 quadernos ó copias del tiempo del Rey Don Juan $2^{\circ}$, és á saber: el $1^{\circ}$, de peticiones de los procuradores de las ciudades en las Cortes de Toledo; el $2^{\circ}$, peticiones de los procuradores de Cortes de Zamora; el $3^{\circ}$, Cortes de Madrigal de 1438; el 4\%, peticiones de los procuradores de las Cortes de Burgos; y el 5", Cortes de Madrid de 1435.

- Numero 70. Un legajo sin cubierta que contiene 16 copias de privilegios, cartas, cedulas, ordenamientos, mercedes y donaciones de los Reyes Catholicos Don Alonso 11, Don Enrique $3^{\circ}$ y 4\%, y otros señores Reyes de España.

- Numero 71. Un legajo sin enquadernar que contiene 32 copias de cartas, cedulas reales y otros varios instrumentos del tiempo del Rey Don Enrrique $4^{\circ}$. 
- Numero 72. Un legajo sin enquadernar que contiene 46 copias de cortes y pragmaticas de los señores reyes de España, és á saber: de Madrid, de Valladolid, Segovia y Cordova por los Señores Carlos $5^{\circ}$, Phelipe $2^{\circ}$ y $3^{\circ}$.

- Numero 73. Un legajo sin cubierta que contiene 9 quadernos de ordenamientos, pragmaticas y cortes de los señores reyes Don Alonso 11 ,

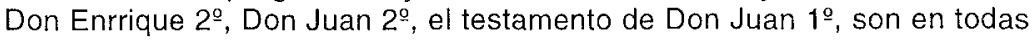
11 copias.

- Numero 74. Otro legajo cubierto de pergamino que contiene 3 quadernos de cedulas, provisiones y cortes del tiempo de los señores reyes Don Phelipe segundo, $3^{\circ}$ y $4^{\circ}$ y son en todas 18 copias.

- Numero 75. Un legajo sin cubierta que contiene 30 copias de ordenamientos, cedulas, privilegios, fueros, ordenanzas, cartas y otros instrumentos de San Fernando, varios Alfonsos Reyes Catholicos y otros señores reyes. $Y$ el quaderno de leyes del Maestre Jacob.

- Numero 76. Un legajo sin cubiertas que contiene el indice de los provilegios que se conservan en el archivo del Ymperial Convento de San Clemente de Toledo, memorias de papeles del Archivo del Real de monjas cirtercienses dél, y a su continuación varias copias de donaciones, escrituras y otros instrumentos que en todas son 90 .

- Numero 77. Un legajo sin enquadernar que contiene varias noticias y copias pertenecientes á los nombres de los antiguos tributos y otras cosas en que se incluyen varios privilegios é instrumentos antiguos.

- Numero 78. Un legajo sin cubierta que contiene 5 quadernos con 18 copias y empieza con las ordenanzas de toledo sobre el ganado bacuno; sigue: titulos de los Montes de Toledo; y finaliza con memorias de las Santas Virgenes Justa y Rufina.

- Numero 79. Un legajo sin enquadernar que contiene 20 copias de Hermandades, vieja y nueva, general y de Toledo, Talavera y Ciudad Real y otros y entre ellas algunas impresas.

- Numero 80. Un legajo sin enquadernar que contiene dos quadernos: $1^{\circ}$, inscripciones sepulcrales que éran 7 piezas y falta la del numero 6 ; y el $2^{\circ}$, privilegios de la villa de Alarcon.

- Numero 81. Un legajo sin cubierta que contiene 2 quadernos: $1^{\circ}$, Fuero de la Villa de Molina, dado por el conde Don Amalrrich; $2^{\circ}$, nota de las obras de Juan Alonso de Madirid.

- Numero 82. Un legajo sin enquadernar que contiene 4 quadernos: el $1^{\circ}$, permuta de la villa de lucena por las tierras de la Arrizafa; el $2^{\circ}$, razon del derecho que Su Magestad tiene á la abadia de Benevivere de canonicos reglares de san Agustin en la diocesis de Palencia; $3^{\circ}$; varios privilegios y papeles, algunos impresos, pertenecientes al marques de Villena; y $4^{\circ}$, diferentes papeles sueltos tocantes al mismo y sus lugares.

- Numero 83. Un legajo sin cubierta que contiene 13 quadernos: el 1ㅇ, una obra de Virgilio philosopho arabe cordoves, copiada en 6 quadernillos; el $2^{\circ}$, fragmento de la Historia Universal de Don Alonso el Sabio; el $3^{\circ}$, Anales terceros toledanos; el $4^{\circ}, 5^{\circ}$ y $6^{\circ}$, varios privilegios, cartas, cedulas y 
ordenamientos reales; el $7^{\circ}$, Vida de san Desiderio por el rey Sisebuto, cartas de éste Rey y otros de Tarra, Bulgarano y otros godos, y asimismo las de Elipando cotejadas con el manuscrito gotico; el $8^{\circ}$, Pasio B. Saturnini; el $9^{\circ}$, cotejo de las obras de Paulo Orosio; el 10, yndice del libro de cosas de don

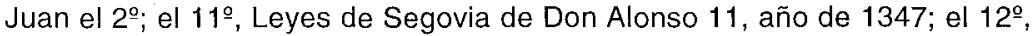
juramento para la deliberacion de los Grandes y Cavalleros en las Cortes de Toledo de 1538 sobre la sisa; y el 13으, noticia de los quadernos de la libreria de la Santa Yglesia de Toledo que tratan de primacia y bulas con copia de algunos.

- Numero 84. 1 quadernos sin cubierta que es el papel de Don Agustin Riol sobre archivos y papeles.

- Numero 85. Un legajo con cubierta de pergamino que contiene 2 quadernos, á saber: el $1^{\circ}$ de sellos en limpio para abrirse y son 31 pliegos en papel; el $2^{\circ}$ de sellos de cera de Reyes de Castilla y Leon, que son 10 vitelas sacadas tambien en limpio por don Francisco Palomares.

- Numero 86. Un legajo sin cubierta que contiene 23 quadernos de copias de papeles aceitados copiados é imitados por el citado Palomares, és á saber: varios privilegios, arboles genealogicos, ereccion de canongias, ruedas ó signos de privilegios y otros instrumentos.

- Numero 87. Un legajo sin cubierta que contiene 2 quadernos con 195 copias de sellos de privilegios de los reyes don Fernando el $4^{\mathbf{0}}$, don Sancho el $4^{\circ}$ y otros señores reyes de Epaña, y asimismo varias muestras de letras antiguas y sellos de las bulas de primacia y otros algunos de particulares copiados é imitados por Palomares.

- Numero 88. Un legajo con cubierta de pergamino que contiene 2 quadernos: el $1^{\circ}$ en vitela de signos y ruedas con algunos principios y fechas de los provilegios de los reyes que se hallan en el archivo de la Santa Yglesia de Toledo desde don Alonso $6^{\circ}$ que conquistó ésta ciudad hasta don Juan $1^{\circ}$ y son 200 vitelas; el $2^{\circ}$ de sellos de plomo en limpio que contiene 4 vitelas, y asimismo un quaderno de varias monedas arabes, puestas sobre pliegos, todo de mano del mismo Palomares.

- Numero 89. Un legajo con cubiertas sueltas de cartones que contiene 40 quadernos de muestras de varios caracteres y letra antigua en que se hallan escritos diferentes codices, privilegios y bulas y otros documentos del archivo de Toledo y otros imitados por dicho Palomares en papel aceitado.

- Numero 90. Un legajo sin cubierta que contiene una cedula original de facultad real concedida á Juan de Ayala con su copia imitada por Palomares y asimismo 20 copias de privilegios, cartas reales, inscripciones y fragmentos del Misal y Brebiario goticos entre los quales se halla la de una bula de Urbano $2^{\circ}$ á don Bernardo, arzobispo de Toledo, confirmando la primacia de aquella Santa Yglesia, imitadas todas por Palomares.

- Numero 91. Libro de diferentes quentas de entrada distribucion de rentas reales y gasto de casa real en el reynado de don Sancho 4, era de 1331 y 1332, que son años de 1294 y 1293, sacado de un tomo original en folio, que se guarda en la libreria de la Santa Yglesia de Toledo. 
- Numero 92. Un legajo con cubierta de pergamino que comprende 24 quadernos con 169 copias pertenecientes á la fundacion de la Santa Yglesia de Toledo y á sus prelados, és á saber desde don Bernardo a don Juan Martinez Siliceo.

- Numero 93. Un legajo con cubierta de pergamino que contiene 17 copias ó quadernos de la Historia en castellano de los arzobispos de Toledo desde don Gonzalo Garcia hasta don Bernardo de Rojas; é tomo $2^{\circ}$ de dicha Historia.

- Numero 94. Un legajo sin cubierta que contiene 8 quadernos con 58 copias de ynstrumentos de la fundacion de la Santa Yglesia de Toledo, sus dignidades, prevendas, hermandades con otras yglesias de España y reliquias, fundaciones de la de Guadix, Baza y Talavera y donaciones de los señores reyes á los arzobispos de Toledo.

- Numero 95. Un legajo cubierto de pergamino que contiene 4 quadernos con 70 copias respectivas á la Santa Yglesia de Toledo, és á saber: el $1^{\circ}, 38$ copias de instrumentos y noticias de primacia con Tarragona; el $2^{\circ}, 20$ de ynmunidad; el $3^{\circ}, 5$ de Luctuosa; y el 4ㅇ, 7 de conservatorias.

- Numero 96. Un legajo con cubierta de pergamino que contiene varios quadernos con 20 copias tocantes al cardenal Don gil de Albornoz, maestros del Colegio de Bolonia, a concilios, constituciones sinodales, luctuosa, vasallos y preeminencias, cortes y simultaneas, y varios papeles pertenecientes a Don Domingo Pasqual, Don Juan ynfante de Aragon y Don Sancho ynfante de Castilla.

- Numero 97. Otro legajo cubierto de pergamino que contiene $71 \mathrm{co}-$ pias de algunos extractos de concilios y constituciones ecclesiasticas y sinodales especialmente de Toledo, privilegios y concesiones de decimas, bulas y cedulas tocantes á aquella santa yglesia.

- Numero 98. Un legajo sin cubierta que contiene 3 quadernos: el 1, B. Gregorii episcopi Hiberitani explicatio in cantica canticorum, de que hay solo la prefacion en 2 piezas; el $2^{\circ}, 2$ opusculos de Justo obispo de Urgel, y de Justo obispo de Toledo, en 6 piezas; y el $3^{\circ}$, kalendario ritual de la Santa Yglesia de Toledo en 3 quadernillos.

- Numero 99. Un legajo sin cubierta que comprende 28 quadernos de papeles é instrumentos sacados de los archivos de la ciudad é yglesia de toledo pertenecientes á una y otra y entre éllos diferentes cartas de algunos señores reyes.

- Numero 100. Un legajo con cubierta de pergamino que contiene 17 quadernos con 182 copias de privilegios y documentos pertenecientes á la fundacion y dotacion del monasterio de San Servando de Toledo, donaciones á aquella santa yglesia y otras por los señores reyes de Castilla con algunos testamentos suios, bulas, ordenanzas de arzobispos de Toledo y otros de la misma clase.

- Numero 101. Un legajo con cubierta de pergamino que contiene 13 quadernos; los 4 primeros de bulas y papeles pertenecientes á concilios especialmente provinciales de España, y los 9 restantes de constituciones sinodales de Toledo y Tarragona. 
- Numero 102. Un legajo con cubierta de pergamino rotulado Varios que contiene 4 quadernos: el $1^{\circ}$, copia del concilio de Peñafiel; $2^{\circ}$, extracto de los codices goticos de Toledo y copia de canones del concilio niceno que contienen; $3^{\circ}$, medidas de Salamanca y á éllas reducidas las griegas, romanas y hebreas; y $4^{\circ}$, coleccion de privilegios y bulas á favor de la Santa Yglesia de Toledo en numero 26.

- Numero 103. Un legajo cubierto de pergamino que contiene 13 quadernos de noticias, yndices, extractos y cotejos de codices de concilios de España hechos por Ambrosio de Morales, Vazquez de Marmol, Don Juan Baptista Perez y algunas notas del padre Burriel á los concilios compostelano, legionense y de Coyanza.

- Numero 104. Un legajo cubierto de pergamino que contiene 31 quadernos; los primeros pertenecientes á decimas, tercias é immunidad entre los quales se halla una copia remedada por Don Francisco Palomares de bula de Gregorio 9o sobre tercias, y los restantes de privilegios, cartas, fueros, despachos, cortes, contratos y capitulaciones matrimoniales de diferentes reyes con el testamento del rey Don Alonso $8^{\circ}$, el de las Nabas, hecho en Fuentidueña á 8 de diciembre era 1242, año 1204.

- Numero 105. Un legajo sin cubierta que contiene 7 quadernos: el $1^{\circ}$ copia imperfecta del manuscrito de las obras astronomicas del rey Don Alonso el Sabio; el $2^{\circ}$, fragmentos goticos; el $3^{\circ}$, notas y apuntaciones sobre el manuscrito rotulado Enrrique de Villena sobre Virgilio; el 4. Prologo de la Genealogia de los Dioses, de Juan Bocacio; el $5^{\circ}$, de varios privilegios del rey Don Sancho; el 6은 34 copias de privilegios de vasallos; y el $7^{\circ}, 2$ copias de inscripciones sepulcrales de la parroquia de Santiago (vulgo del Arrabal) de Toledo, y del convento de la Concepcion Franciscana de la misma ciudad.

- Numero 106. Un legajo sin cubierta que contiene 24 quadernos pertenecientes á la junta de Patronato y derechos deducidos por España para el ultimo concordato celebrado con la corte romana.

- Numero 107. Un legajo cubierto de pergamino con 5 quadernos que contienen varias copias de papeles pertenecientes al Real Patronato, camara, resultas, á saber: $1^{\circ}$ quaderno, 3 copias; $2^{\circ}, 2 ; 3^{\circ}, 4 ; 4^{\circ}, 1 ; 5^{\circ}, 1$ y dos pliegos sueltos, el uno impreso.

- Numero 108. Un legajo con cubierta de pergamino que contiene 18 quadernos de copias de bulas é instrumentos de reconocimiento del derecho metropolitano y sujeccion al arzobispo de Toledo, por diferentes obispos sufraganeos y algunos abades, y asimismo de otros derechos y donaciones respectivas, és á saber: de Palencia, 27 copias; de Cuenca, 12; de Cordova, 14; de Baeza, 11; de Jaen, 10; de Sigüenza, 13; de Osma, 10; de Segovia, 10; de Segorve y Albarracin, 13; de Cartagena 2; de Valladolid, 3; de Avila, 4; de Plasencia, 4; de Zamora, 2; de Coria, 1; de Lisboa, 2; de Almeria, 1; de Cobarrubias, 1; de varios monasterios 12; de derechos de obispos y sufraganeos, 3; y 2 de Oviedo.

- Numero 109. Un legajo sin cubierta que contiene 5 quadernos: los 4 sobre el estatuto de limpieza de sangre de la Santa Yglesia de Toledo y de otras comunidades de España, y el 5ㅇ, copia de una carta de privilegio que el rey don Juan el $2^{\circ}$ concedió a un hijodalgo. 
- Numero 110. Un legajo sin cubierta que contiene dos quadernos: el $1^{\circ}$ copia de yndice de la libreria de la Santa Yglesia de Toledo y el $2 .{ }^{\circ}$ una carta del cardenal Don Juan Martinez Siliceo al señor Emperador don Carlos $5^{\circ}$ sobre el adelantamiento de Cazorla.

- Numero 111. Un legajo sin cubierta con 36 piezas que contienen el yndice de ynstrumentos copiados en el archivo de la Santa Yglesia de Toledo durante la comision en que entendió el Padre Andres Burriel.

- Numero 112. Un legajo sin cubierta que contiene 9 quadernos de ynstrumentos sacados de los archivos de la yglesia y ciudad de Murcia: el $1^{\circ}$ con 158 copias en razon de justificar que el señor emperador Don Alonso conquistó á Toledo, restableció y erigió, fundó y dotó su Yglesia Metropolitana; el $2^{\circ}$ con una en 14 pliegos en que se prueva que el Santo Rey Don Fernando $3^{0}$ conquistó y pobló á Sevilla, restableció, erigió y dotó su Yglesia Metropolitana; el $3^{\circ}$, una copia en 8 quadernos que justifican haber sido erigida, fundada y dotada por el señor rey Don Alonso 10, aumentada y enrriquecida por los señores reyes sus sucesores la santa yglesia de Cartagena; el $4^{\circ}$, catalogo de sus obispos; el $5^{\circ}$, ynventario del archivo de la misma yglesia de Cartagena en 9 quadernillos; el 60. Ynventario del Archivo de la ciudad de Murcia en 6 quadernos; el $7^{\circ}$, Yndices de los quadernos de cortes y tratados de paces que se hallan en el mismo archivo; el $8^{\circ}$, un privilegio y ordenanza del señor rey don Juan de Aragon para que los clerigos que no fuesen naturales de sus dominios no pudiesen obtener en éllos beneficios ni otras prevendas ecclesiasticas, expedido el año de 1396; y el $9^{\circ}$, representacion y cartas de Don Asensio de Morales al señor Carbajal (y sus respuestas) remitiendo instrumentos.

- Numero 113. Un legajo en folio sin cubiertas que contiene 10 quadernos de copias de papeles pertenecientes á la Historia Civil y Ecclesiastica, especialmente de la Santa Yglesia de Cuenca, con 2 planes de élla y asimismo varios sobrepuntos de derecho ecclesiastico y otros.

- Numero 114. Un legajo sin cubierta que contiene 3 quadernos: el 1ㅜ, ynventario del archivo de la yglesia de Orihuela en 6 piezas; el $2^{\circ}$, compulsa de privilegios, bulas y otros ynstrumentos pertenecientes á Historia Civil y disciplina Ecclesiastica de España, sacada de orden de S.M. de los archivos de la cathedral de la ciudad y obispado de Orihuela por don Ascensio de Morales oydor de Sevilla, y está en 30 piezas; y el $3^{\circ}$ en 3 quadernillos: el $1^{\circ}$ de privilegios, donaciones y bulas pertenecientes a dicha ciudad, en 7 piezas; el $2^{\circ}$, reconocimiento del archivo de la ciudad de Tarragona, en 5 piezas; y el $3^{\circ}$, diferentes cartas del expresado Morales y otros; todas copias.

- Numero 115. Un legajo sin cubierta que contiene 22 quadernos de yndices de ynstrumentos que se hallan en los archivos de varias santas yglesias, és á saber: de Oviedo, de Santiago, de Lugo, de Tuy, de Ceuta, de Orense, de Palencia, de Valladolid y de Barcelona; y en el ultimo quaderno se contienen las copias de los yndices de las yglesias de Astorga, Leon, Santander y otros de papeles de los señores reyes catholicos y del patronato del reyno de Granada; y asimismo un extracto de diferentes papeles é instrumentos del Real Archivo de Barcelona y del de Nuestra Señora de Sarrateix. 
- Numero 116. Un legajo sin cubierta que contiene 3 quadernos: el 10 de ynstrumentos y noticias que aseguran la existencia de las ordenes de Calatrava, Alcantara, San Juan, Santiago, Monteanges, alemanes o Teutonica, templarios y San Pedro de Gumiel en la ciudad de Cordova, y son 53 copias; el $2^{\circ}$ de memorias para la historia de la yglesia de Coria que contiene 36 copias; y el $3^{\circ}$, asimismo de memorias para la historia de la Santa Yglesia de Sigüenza en 66 copias.

- Numero 117. Un legajo sin enquadernar que contiene 4 quadernos: el $1^{\circ}$, de usu et authoritate legis gotica, sive libris legis gothorum (vulgo Fuero Juzgo) in Cathalonia sive Gothia, et Septimania, sive provincia Narbonensi; apuntamiento hecho por don Juan Lucas Cortés escrito al fin del siglo pasado ó principios del presente; y sigue de letra del padre Burriel una nota de los codices del Fuero Juzgo que hay en la libreria de la Santa Yglesia de Toledo, segun le ordenaron los padres Sarmiento y Mecolaeta; $2^{\circ}$, Yndice de varios testimonios y autos sobre la preferencia entre Toledo y Burgos en cortes y otros actos publicos; $3^{\circ}$, ynstruccion que dio el rey don Phelipe $3^{\circ}$ á Don Juan Fernandez Pacheco, duque de Escalona, su embajador en Roma, fecha en Lerma á 8 de junio de 1603; y 4º, matriculas é inventario de los instrumentos del archivo del real convento de san Marcos de Leon, hecho con despacho y provision de 6 de marzo de 1658, á pedimiento del fiscal del Real Consejo de las ordenes. Está impreso.

- Numero 118. Un legajo sin enquadernar que contiene 6 quadernos: el $1^{\circ}$, de apuntamientos sacados por el padre Burriel de algunos codices de la Santa Yglesia de Toledo acerca de las obras de varios santos y escritores ecclesiasticos españoles como Etherio y Beato, el Abad Sanson, San Ysidoro y otros; 2 , epistola de Elipando en nombre de los obispos y fieles de España al concilio de Francford, inedita, sacada fidelisimamente por el mismo Padre del codice gotico de dicha yglesia de el que se sacáron las impresas por el maestro Florez y adjunto el cotejo de éstas con las del codice hecho por Burriel; $3^{\circ}$, concilio de Burgos año de 1074, yndice de concilios segun el codice gotico de España, la Vision de Tajon, cathalogo de obispos de Leon y abades de Oña, cartas de san Braulio, elogio de san Ysidoro, versos de san Yldefonso y otras cosas ecclesiasticas de España, todo extracto por el mismo padre Burriel; 4므. Vizentti de Bandelis de Castronovo Ferdonensis diocesis ordinis Praedicatorum, tractatus de singulari puritate et prerrogativa concepcionis salvatoris Nostri thesu Christi, extractado por el padre Burriel; 5, D. Francisci de Mendoza et Bobadilla asertiones de unitate naturali internos et Christum per esum carnis eius et per potum sanguinis eius, que parece original; y $6^{\circ}$, Prefacio é yndice del Apologetico de Palma por los nuevos conversos de Toledo.

- Numero 119. Un legajo sin enquadernar que contiene 4 quadernos: el $1^{\circ}$, yndice de los 3 tomos de la coleccion manuscrita de Don Juan Baptista Perez que se conservan en la libreria de la Santa Yglesia de Toledo; $2^{\circ}$, extractos de otros tomos del mismo Perez que se guardan en la misma libreria y comprenden donaciones de reyes á arzobispos é yglesia de Toledo, y donaciones de arzobispos á canonigos, y aniversarios de la misma yglesia, noticias de la vida del cardenal don Gil de Albornoz; $3^{\circ}$, observaciones sobre la ficcion del Aguamanil y ruinas de la capilla de san Tirso en Toledo y de la 
carta de silo, ó caxila, una de Esteban de Garibay á Phelipe $2^{\circ}$ y otras de Christoval de Palomares, Bibliothecario de la Santa Yglesia de Toledo á don Juan Baptista Perez; respuesta de ésta con su parecer separado y otra del licenciado Espinosa á Palomares escrita sobre el mismo asunto, todas copiadas de la libreria de Toledo; y el $4^{\circ}$, copia del concilio de Oviedo sacada de los mismos codices de Perez y cotejada con el impreso por el cardenal Aguirre.

- Numero 120. Un quaderno que contiene la noticia de Pedro Salazar de Mendoza, canonigo de Toledo, sus primeros estudios y grados, la de su obra intitulada Monarquia de España, algunas notas á élla, sus yndices y lamina en cobre para la impresion de dicha obra.

- Numero 121. Un tomo enquadernado y sin cubierta que es coleccion de varios papeles curiosos, y empieza con una carta del Rey de Francia á el cardenal d'Etrees en Versalles á 6 de septiembre de 1688 á que sigue el Reyna de Francia, memorial de la Santa Yglesia de Toledo al Rey para que se sirviese mandar recoger el Breve expedido por el Papa en 8 de agosto de 1687 para que el cardenal Aguirre pudiese obtener prevenda en aquella Santa Yglesia y otras tocantes al mismo asunto y diferentes papeles politicos y obras de la venerable madre Maria de Jesus de Agreda.

- Numero 122. Un legajo sin cubierta que contiene la copia del testamento y codicilo del yllustrisimo don fray Francisco Ximenez de Cisneros, cardenal arzobispo de toledo, sacada del archivo de la misma ciudad.

- Numero 123. Un legajo sin cubierta que contiene una coleccion de privilegios y papeles pertenecientes a la villa de Talavera y son en todas 20 copias.

- Numero 124. Un rollo en que está copiada la inscripcion y cruz del sepulcro que se halló en un olivar fuéra de Talavera de un hombre llamado Litorio de la era 548, año de Christo 510; el venerable don fray Francisco Ximenez, arzobispo de Toledo, hizo trasladar el de 1512 á la hermita de Nuestra Señora del Prado, extramuros de dicha villa donde se conserva.

$Y$ en ésta forma se concluió éste ynventario del dia 8 del presente mes habiendo asistido el expresado padre Rector todos los dias, y por su ausencia en las ocasiones que tubo precision de hacerla el padre ministro del mismo colegio é igualmente Don Francisco Morán, Don Joseph de Castro y Don Justo del Cerro, escribientes de la Real Bibliotheca que fuéron en $\mathrm{mi}$ orden para el mismo fin, y mas exacto cumplimiento de lo mandado por Su Magestad, y para que conste lo firmo en Madrid á 9 de julio de 1762 años. = Don Juan de Santander.

Es copia del ynventario original que pasaré á las reales manos de S.M. por medio del expresado Marques de Campo de Villar, su secretario del despacho universal de Gracia y Justicia, y la entregó al reverendisimo padre Diego de Rivera, rector del colegio Ymperial de la Compañia de Jesus de ésta Corte, para que le sirva de recivo y resguardo en consequencia de lo mandado por S.M. en las Reales Ordenes que se citan en él y se han cumplido exactamente. Madrid 31 de julio de 1762 años. = Don Juan de Santander». 
El segundo se titula Memoria de los libros y papeles manuscritos que se hallaban en el aposento del padre Andrés Marcos Burriel de la Compañia de Jesús, además de los correspondientes a la comisión que tuvo en Toledo de Real Orden, compuesta en Madrid el día 1 de agosto de 1762 por el citado Juan de Santander. En ella, al igual que en el anterior, se nos indica que todos los tomos, legajos y cuadernos citados, en que no se expresa el tamaño son en folio, y también que todos ellos - son un total de 68-, fueron entregados por el Padre Diego de Rivera, como obsequio, al Monarca, el cual los dejó depositados en su Real Biblioteca. Examinemos este repertorio:

«- Numero 1. Tractatus de vita moribus et regimine principium sive comentarius in primum librum regum: auctore Pedro Infante Aragoniae ef qui ordinen fratrum minorum ingresus obiit anno 1380 ad Dom. Petrum regem Aragoniae, ex fratre Nepotem excriptus ex ipso authographo membranaceo in colegio Astigitano, societatis lesu asservato; copia moderna en un tomo enquadernado en pergamino.

- Numero 2. Un legajo en $4^{\circ}$ con cubierta de papel que contiene las lecciones variantes de la Biblia Gotica Complutense hasta el Libro de Josué, sacadas por Don Antonio Ruiz de Quesada por encargo del Padre Andres Burriel.

- Numero 3. Un tomo papel sin enquadernar que contiene cinco quadernos, és á saber: Calixti $2^{\circ}$ Papae, de Miraculis Beati Jacobi Apostoli liber $1^{\circ}$ eiusdem, de translatione corporis Sancti Jacobi apostoli, ab Hierosolimis in Galeciam liber $1^{\circ}$ de itinere ad S. Jacobum liber $1^{\circ}$ Homiliae sive sermones quatuor in vigilia, et festo act translatione eiusdem $\mathrm{S}$. Jacobi quae celebratur tertio kalendas jannuarii cum Epistola Calixti Papae; copiado de orden del Padre Andres Burriel de un tomo de manuscritos del Padre Mariana pertenecientes al archivo de su colegio de la Compañia de Toledo.

- Numero 4. Un quaderno descosido y sin cubierta que contiene las obras siguientes: Don Leandri ad Florentinam sovorem de institutione Virginum; ittem, Libellus de contemptu mundi cum castigationibus Hieronimi Torres Pintiani, qui est Alvari Gometii de Castro carmina Gaspari Quiroga dun sacro Rot Tribunali designatus esset adiunsit; accedunt opuscula quaedam D. Martini Dunvensis, episcopi ex Isidoro de viris illustribus videlicet ex Gregorii Turonensis historia et ex concilio toletano decimo; item eiusdem liber pro repellenda janctantia supervia et alia quaedam; denique titulum (sic) Bibliotheca á Domino Ysidoro editum; item alium titulum pigmentarii et scriptoril. Es copia del principio del siglo pasado ó del fin del antecedente.

- Numero 5. Paenitentiale vetustisimum é codice Gothico Bibliotecae Garsiae de Loaysa era 1143 ex arato, anno 1754, á P. Andrea Marco Burriel excriptum. Un tomo enquadernado en pergamino.

- Numero 6. Un tomo en $4^{\circ}$ escrito en vitela enquadernado y cubierto de terciopelo carmesí que se intitula en la primera oja Sermones secundum 
fratrem Thomam de Aquino ordinis Praedicatorum; siguen dichos sermones hasta la pagina 190, y en la 191 se halla otra obra cuyo titulo dice asi: Incipit expositio in credo in Deum secundum fratrem Thoman de Aquino ordinis fratrum Praedicatorum y acaba pagina 227, y á la 228 empieza otra obra, expositio Pater noster, de la qual solo hay la primera pagina y falta al codice todo lo demás.

- Numero 7. Un legajo sin cubierta que contiene una carta del Monasterio de San Dionisio de Paris al cabildo de Toledo acerca de la lampara que éste cambió y dotó para la capilla de dicho monasterio de donde se sacó el cuerpo de San Eugenio. Hallandose al fin de ésta carta las inscripciones de dicha lampara asimismo contiene la ortographia de la $\mathrm{G}$ y de la $\mathrm{J}$ de cuyo opusculo no consta el autor; las anotaciones de Francisco Turriano (de Torres), jesuita in libris Beat. Ambrosii de bono mortis y varias cartas y opusculos del maestro Albar Gomez de Castro sobre algunas de San Ambrosio; son en todas 19 copias.

- Numero 8. Un legajo en $4^{\circ}$ sin cubierta que contiene Disertaciones ecclesiasticas del excelentisimo señor Marques de Mondexar, en 28 quadernos y empieza por la disertacion $4^{\circ}$, quaderno 14.

- Numero 9. Un legajo sin cubierta que contiene una carta y un discurso de fray Lucas Ramirez sobre el misterio de la concepcion en 19 de junio de 1760.

- Numero 10. Un legajo sin cubierta que contiene tambien algunos quadernos en $4^{\circ}$, todo perteneciente á la vida de San Fernando que se halla al fin en 21 piezas, escrita al parecer por don Juan lucas Cortes, segun una cedula original que se expidió para éllo y está en el mismo legajo donde tambien se halia el plan y descripcion de la capilla de Nuestra Señora de los Reyes de Sevilla con la inscripcion hebrea del sepulcro de San Fernando y su version latina por don Francisco Perez Bayer.

- Numero 11. Un legajo sin enquadernar que contiene 218 copias de privilegios, cartas, donaciones, ventas, testamentos, interrogatorios, burlas y otros documentos y extractos pertenecientes á la causa de beatificacion de la venerable ynfanta Sancha Alfonso, con dos estampas, la una en papel grande y la otra en pequeño, impresas despues de la translacion de su cuerpo desde el Monasterio de Santa Eufemia ál de Santa Fée la Real de Toledo que se hizo de real orden el año de 1608. Está entre dichos papeles una copia simple de la declaracion que hizo en Toledo á 20 de enero de 1757 el padre Andres Burriel, perito nombrado para el reconocimiento de los instrumentos sacados para dicha causa del archivo del expresado monasterio de Santa Fée del orden de Santiago.

- Numero 12. Un legajo en $4^{\circ}$ con cubierta de papel que contiene la vida del yllustrisimo señor don Martin de Ayala, arzobispo de Valencia, escrita por el mismo, sacada por don Luis de Salcedo de una copia que hizo por el original que estába en Ucles, el sargento Torrijos y añadido al fin un catalogo de erratas y sus enmiendas.

- Numero 13. Un tomo enquadernado en pergamino que contiene la vida de doña Estefania Manrrique de Castilla, fundadora de la casa profesa de la Compañía de Jesus, escrita por el padre Pedro de Rivadeneira de la 
misma Compañia, copiada para el padre Burriel del exemplar que se guarde en el Archivo de Toledo.

- Numero 14. Un tomo enquadernado en pergamino que contiene la historia de Alexandro Magno, escrita por Quinto Curcio, y traducida al castellano por Pedro Candido de Simbre, que la dirigió á Phelipe Maria tercero, duque de Milan y de Pavia, conde de Antequera y señor de Genova, año de 1438 á 20 de abril en Milan; escrita por Thomás de Lira Aleman, és excelente copia, mui curiosa con los titulos de los libros y capitulos, letras iniciales y divisiones de vermellon.

- Numero 15. Un legajo en $4^{\circ}$ sin enquadernar que contiene tres quadernos de fragmentos de la Historia de don Sancho rey de Castilla, y de los Reyes Catholicos. Están de letra del señor rey Don Fernando 6, año de 1725.

- Numero 16. Un tomo de letra antigua enquadernado en pergamino que contiene las Cronicas de san Fernando $3^{\circ}$, don Alonso 10 , don Sancho $4^{\circ}$, don Fernando $4^{\circ}$ y don Alonso 11.

- Numero 17. Un tomo enquadernado en pergamino que contiene las cronicas de Castilla desde don Sancho el Deseado hasta los tiempos de don Sanchos (sic) 4․, llamado el Bravo, hecha copiar año de 1755 por el padre Burriel de un manuscrito antiguo en papel y letra del siglo 15 que fué de la libreria de don Garcia de Loaysa, arzobispo de Toledo. Tiene dentro un quaderno de cotejo de la cronica general impresa por Florian de Ocampo con un tomo manuscrito de don Juan Antonio de las infantas doctoral entonces, y hoi dean de la Santa Yglesia de Toledo.

- Numero 18. Un tomo enquadernado en pergamino que contiene la cronica brebe de Castilla desde don Alfonso el Catholico hasta don Henrrique $3^{\circ}$, escrita por el despensero de la reyna doña Leonor. Copiada año de 1754 de orden del padre Burriel de un manuscrito acephalo en papel y letra del siglo 15 de la libreria del arzobispo don Garcia de Loaysa.

- Numero 19. Un tomo enquadernado en pergamino que contiene la Cronica del rey don Enrrique $4^{\circ}$, hijo del rey don Juan el $2^{\circ}$ por Diego Enrriquez de Castilla, capellan y de su consejo. Es copia de letra antigua bien escrita y conservada.

- Numero 20. Un tomo enquadernado en pergamino que contiene la Cronica de don Enrrique $4^{\circ}$, rey de Castilla y de Leon, por Alonso de Palencia, chronista de los Reyes Catholicos, copiada de orden del P. Burriel de un manuscrito antiguo de don Juan Antonio de las Ynfantas entonces canonigo doctoral y hoy dean de la Santa Yglesia de Toledo.

- Numero 21. Un tomo enquadernado en pergamino que contiene un memorial ó registro breve de los lugares donde el Rey y la Reyna Catholicos estubiéron cada año desde el 68 hasta que Dios los llevó para si. Escrito por el doctor Lorenzo Galindez de Carbajal del Consejo de dichos Reyes copiado para el P. Andres Marcos Burriel de la Compañia de Jesus.

- Numero 22. Un tomo enquadernado en pergamino de los Anales de la Corona de Aragon por fray Pedro de Lovera del orden de san Agustin y empieza desde el reynado de Witiga rey godo y acaba en el libro $3^{\circ}$ de dicha Historia donde descrive la vida del rey don Alonso $5^{\circ}$ no tiene nota de año. 
- Numero 23. Un tomo en quarto de enquadernacion antigua y maltratado que contiene una relacion de la batalla de Pavia y prision del rey Francisco de Francia escrita en Talabera á 25 de noviembre de 1544 y dedicada á don Pedro Davila, marques de las Navas, que la mando escrivir al autor cuyo nombre no consta. Parece por lo bien escrita que és la primera copia en limpio que sacó para presentársela.

- Numero 24. Un legajo sin cubierta que contiene un quaderno de la Historia de la ciudad de Valladolid sin nombre de autor ni año.

- Numero 25. Un tomo enquadernado en pergamino que contiene las alteraciones populares de Zaragoza por el doctor Bartholomé Leonardo de Argensola, canonigo de Zaragoza, cronista del rey nuestro Señor y en Aragon del mismo reino; parte $1^{\underline{a}}$ copia moderna.

- Numero 26. Un legajo en $4^{\circ}$ sin cubierta que contiene 37 copias de papeles varios pertenecientes á apuntaciones historicas y asimismo á la historia del emperador don Alonso y otros con varias cartas de eruditos al Padre Burriel (está rotulado Varias cartas de erudicion) por don Serafin Thomás Miguel, del orden de Santo Domingo, escritor de dicho Santo Patriarca.

- Numero 27. Un legajo en 4ำ con cubierta de papel que contiene la historia de Berberia de Diego Suarez Montañes en 16 quadernos, copia de letra del siglo pasado.

- Numero 28. Un tomo que contiene dos quadernos sueltos: uno de letra moderna que és carta del doctor Frias de Albornoz, natural de Talavera, contra el maestro Andres Resende en 27 pliegos en que prueva que Talavera se llamó antiguamente Elbora y que de élla fué natural san Vicente de Avila; y otro de letra del siglo proximo pasado que és Historia de Talabera en 30 quadernos, no tiene autor ni nota de año.

- Numero 29. Un legajo en $4^{\circ}$ cubierto de olandilla encarnada que contiene diferentes inscripciones que hizo el padre Burriel para el camino que se abrió en el Puerto de Guadarrama y asimismo la inscripcion sepulcral de Garcia ó Gutierre Fernandes de Oterdelobos que se halla en una piedra negra con otras varias y asimismo diferentes notas de monedas antiguas y desconocidas españolas.

- Numero 30. Un legajo sin cubierta que contiene 34 copias de laminas pertenecientes á la Paleografia que publicó el padre Burriel, varias inscripciones sepulcrales y algunos apuntamientos de historia.

- Numero 31. Un legajo sin cubierta con 5 quadernos que contienen, és á saber: el $1^{\circ}$, quatro inscripciones sepulcrales; el $2^{\circ}$, un mapa en papel aceitado de los caminos de tierra de Toledo; el $3^{\circ}$, una Apologia del padre Gabriel Vazquez de la Compañia de Jesus, pro Jurisditione Ecclesiastica. El $4^{\circ}$, un memorial impreso del lugar y concejo de la Puebla Nueva de la jurisdicion de Talavera al rey don Phelipe $2^{\circ}$ sobre la hidalguia de don Diego Blazquez Sanchez, vecino de dicho lugar de la Puebla Nueva; el $5^{\circ}$, la genealogia tambien impresa de limpieza y nobleza del capitan don Esteban Juan de Veizama y Llamas, pretendiente de habito de Santiago.

- Numero 32. Un legajo sin cubierta que contiene 3 quadernos: el 1丷, Geographia española y descripcion de los rios mas celebres de España y de 
sus costas; el $2^{\circ}$, carta y discurso sobre conclave escrito y dirigido al excelentisimo señor Carbajal por don Alfonso Clemente de Arostegui; el $3^{\circ}$, un quaderno en $4^{\circ}$ con dos cartas de don Gregorio Lopez y don Andres Santos con noticias de la libreria de Huerta y del concilio Telense.

- Numero 33. Un tomo enquadernado cubierto de pemanimo que contiene varios papeles impresos y manuscritos y empieza con uno impreso del voto de defender la pureza de la Concepcion de Maria Santisima hecho en Madrid por la congregacion de la misma immaculada congregacion de San Salvador y siguen otros manuscritos, és á saber: motivos propuestos á la santidad de urbano $8^{0}$ para ayudar la causa catholica de Alemania año de 1632. Relacion de la muerte de Carlos Stuardo, Rey de Ynglaterra, año 1649 y de lo que se ordenó despues acerca de la religion; otra de la muerte de Sixto $5^{\circ}$, su fecha en Roma á 5 de septiembre de 1591; Memoria de los titulos que están puestos en los atahudes de los cuerpos reales que se trasladaron en el monasterio de San Lorenzo el Real por mandado del señor Don Phelipe $2^{\circ}$ en que hay notas marginales de Alvar Gomez, Victoris Episcopi Cummenensis continuacio Historiae ubi reliquit proper; y diferentes cartas del señor Phelipe $2^{\circ}$ y papeles de Historia Ecclesiastica y de erudicion.

- Numero 34. Un tomo enquadernado en pergamino que contiene varios papeles curiosos que constan de su yndice, el qual empieza con una carta del emperador Constantino quando se convirtió á la fée catholica y acaba con una copia del motupropio del Papa san Pio 5ํㅗ sobre la clausura de las monjas.

- Numero 35. Un legajo sin enquadernar que contiene dos quadernos y 13 copias de arboles genealogicos sacadas por orden del padre Burriel de un manuscrito original de don Juan Lucas Cortés encuadernado y cubierto de pergamino que pertenece al archivo de los Duques de Medina-Sidonia.

- Numero 36. Un legajo que contiene tres quadernos: el 1impreso y és un memorial ajustado hecho con citacion y asistencia de las partes del pleito entre Don Juan Pacheco de Mendoza, y Don Joseph Gonzalez Pacheco y otros del apellido Pacheco, sobre la tenuta y posesion del vinculo y mayorazgo que fundó Don Alonso Pacheco despues martir en Salsete; el $3^{o}$, copia simple de executoria de terminos de la villa de Minoya en favor de Don Francisco Pacheco, señor de dicha villa.

- Numero 37. Un tomo enquadernado en pergamino que contiene el repartimiento de Sevilla hecho en élla por el Rey don Alfonso era 1291 años, copia moderna.

- Numero 38. Un tomo enquadernado en pergamino que contiene el estado de la Casa del duque Carlos de Borgoña, y orden de la guerra, puesto todo por escrito por Oliveros de la Marca, cavallero, consejero y mayordomo del dicho duque; trasladado de franceses en castellano, y añadidas dos relaciones de la Casa del Emperador Don Carlos $5^{\circ}$ y del Rey Don Phelipe $2^{\circ}$, copia moderna hecha de orden del padre Burriel, y dedicada al actual duque de Alba.

- Numero 39. Un tomo cubierto con pergamino que contiene 3 quadernos: el $1^{\circ}$, de cortes de la Coruña, manuscrito de letra antigua; el $2^{\circ}$, impreso y és la carta y capitulos que los procuradores de cortes y Junta del Reyno em- 
biáron á suplicár al Emperador; y el 3ํ, manuscrito, que contiene el fuero que el (sic: rey) don Fernando otorgó á la ciudad de Cuenca, és copia de letra antigua.

- Numero 40. Un tomo sin enquadernar que contiene una carta del Padre Andres Marcos Burriel á don Juan Joseph Ortiz de Amaya sobre las leyes, fueros, ordenanzas y quadernos de cortes de Castilla, éscrita en Toledo en $3^{\circ}$ de septiembre de 1751.

- Numero 41. Un legajo sin cubierta que contiene 5 copias: la 1a, sobre capitulaziones del Lizenciado Chinchilla en Bilbao y las quatro restantes sobre fueros de Vizcaya.

- Numero 42. Un legajo sin enquadernar que contiene 2 quadernos: el $1^{\circ}$, copia simple del testamento del Señor Phelipe $2^{\circ}$; y el $2^{\circ}$, varios papeles de catastro, fabricas reales, rentas y otros.

- Numero 43 . Un quaderno en $4^{\circ}$ cosido y sin cubierta que contiene un discurso sobre la importancia de quitar todos los tributos y reducirlos á uno, para desempeño de la Monarquía de España y alivio de los vasallos, por el capitan Don Juan de Fonseca, regidor de la ciudad de Toledo, escrito al parecér el año de 1632.

- Numero 44. Un tomo con cubiertas sueltas de pergamino que trata de la noticia y defensa de las Reales Fabricas de Guadalaxara en 185 pliegos con un arancel ó reglamento general al fin de 13 pliegos para el pago de las maniobras de dicha fabrica.

- Numero 45. Un tomo enquadernado en pergamino que es el informe del Duque de Linares, Virrey de Mexico, hecho en aquella ciudad en 22 de marzo de 1723, sobre La Habana, Campeche y otros parages de Nueva España.

- Numero 46. Un tomo enquadernado en pergamino que contiene parte del despacho, cartas y otros papeles pertenecientes á la embajada extraordinaria de Saboya y republica de Venecia en el ministerio del conde de la Roca y años de 1632 y 1633.

- Numero 47. Un tomo de papeles varios en castellanos cosidos y cubiertos con un pergamino, y son los siguientes: el 1․, relazion de la causa y castigo de Don Carlos Padilla, Don Pedro de Silva y otros; el $2^{\circ}$, un papel sobre que los frayles no publiquen las bulas sino solos los receptores que los cabildos nombraren; el $3^{\circ}$, la novela de emperador Nicephoro Phocs que hizo escrivir Simon Patricio so'sre que no se hagan monasierios ni hospitales, ni se aumenten con posesiones las casas sagradas y religiosas; el $4^{\circ}$, copia del discurso que se dió á Su Magestad en 7 de abril de 1602 sobre el numero de los golpes particulares, que dió milagrosamente la campana de Velilla de Aragon el dia 13 de junio de 1601 y pronostico de los sucesos que acaecerán por éste motivo dentro y fuera de España, escrito por Diego de Salinas y Heraso, criado del rey; el 5, la vida de los Pages de palacio, pintada al vivo por uno que la vió y otros diferentes papeles.

- Numero 48. Un tomo enquadernado en pergamino que contiene lo sucedido en el concilio de Trento desde el año de 1561 hasta que se acabó por don Pedro Gonzalez de Mendoza obispo de Salamanca, hijo de don Yñigo de Mendoza duque del Ynfantado; copiado de otro del dean de Toledo don Juan Antonio de las Ynfantas que tiene al fin de ésta nota. El original de 
ésta copia le tiene en su poder el maestro y cronista Gil Gonzalez de Avila y se copió en el año de 1629 para el yllustrisimo y reverendisimo señor cardenal don Balthasar de Moscoso y Sandoval, mi señor, obispo de Jaen asistente al presente en Roma á 15 de noviembre.

- Numero 49. Un legajo sin cubierta que contiene 15 copias pertenecientes á las laminas y descubrimientos de Granada asi antiguos como modernos és á saber: de los primeros, cartas y disertaciones de don Juan Baptista Perez, Benito Arias Montano y Bartholomé Petorano; y de los ultimos otros de don Luis Francisco de Viana y don Francisco Crespo de Aguero, oidor de áquelia Chancilleria.

- Numero 50. Un legajo sin cubierta que contiene un quaderno de la historia de la cruzada en España por don Francisco Huerta, autor de los Anales de Galicia.

- Numero 51. Epicilegio de las controversias del Real Patronato, narracion historica del origen y restauracion, fundacion, edificacion y dotacion de todas las yglesias metrhopolitanas y cathedrales de España con un compendio historico, juridico y practico sobre el derecho del Real Patronato que de orden de Su Magestad escribe don Gabriel de Olmeda, etc., tomo enquadernado en pergamino.

- Numero 52. Coleccion de los perjuicios que reciben éstos reynos, con los abusos introducidos por la corte de Roma, en Dataria cancelaria y nunciatura, segunda parte del informe que en virtud del real orden hace á Su Magestad Don Gabriel de Olmeda y Aguilar, marques de los Llanos de su consejo y camara, etc., en Madrid año de 1749, está enquadernada en pergamino.

- Numero 53. Apuntamiento ó instrucciones de los fundamentos de hecho y de derecho con que los señores reyes de España y sus tribunales han conocido de tiempo immemorial de todas las causas y negocios del Real Patronato cuya jurisdicion reside hoy en el Consejo de la Camara en que se trata de la justicia de éste Real Patronato de su naturaleza y jurisdicion por don Gabriel de Olmeda y Aguilar, etc., está enquadernado en pergamino.

- Numero 54. Satisfaccion historica, canonica, legal al manifiesto ó demostracin que la santidad del señor Benedicto 14 dió en respuesta del apuntamiento ó instruccion que de orden del Rey, nuestro Señor, y en consequencia de lo prevenido en el articulo 23 del concordato hizieron presente á los excelentisimos señores cardenales Belliga y Aquaviva por don Gabriel de Olmeda, etc., enquadernada en pergamino.

- Numero 55. Discursos sobre el Real Patronato escritos por don Jacinto de la Torre, año de 1749 enquadernados en pergamino.

- Numero 56. Discurso sobre el concordato de 1737 por don Manuel Bentura de Figueroa, canonigo doctoral de la Santa Yglesia de Orense, año de 1749 , tomo enquadernado en pergamino.

- Numero 57. Un quaderno en $4^{\circ}$ con cubierta de papel que contiene la declarazion del Papa del obispado de Cuenca por Balthasar Porreño, escrita el año 1622. 
- Numero 58. Un tomo enquadernado en pergamino que contiene una copia del papel de don Luis de Salazar sobre la consulta del Consejo de Castilla que trata de su institucion, 1ำ tomo. Este papel se escrivió por dicho Don Luis de Salazar (sobre la consulta del Consejo de Castilla) y Castro, caballero, comendador de Zurita y prior general del orden de Calatrava del consejo de las ordenes y cronista mayor de Castilla de orden del rey dirigida al Duque de Veraguas, presidente de ordenes.

- Numero 59. Un legajo sin cubierta que contiene 6 cuadernos: el $1^{\circ}$, con 3 papeles sobre perjuicios de la corona de España en el trueque del Paraguay y los cinco restantes de cosas de los padres de la Compañia, asi en aquella provincia como en el reyno de Portugal, és á saber: $1^{\circ}$, memorial que el padre provincial de la provincia del Paraguay y entregó al marques de Valdelirios para que suspendiese las disposiciones de la guerra entre los yndios de las misiones; segundo, extracto de una informacion de 12 testigos hecha de oficio por el doctor don Juan Ygnacio de Lacoyzqueta, vicario de santa Fée de la Veracruz, sobre la falsedad del libelo infamatorio en lengua portuguesa (nombrado Republica Americana), Relacion de lo sucedido en la persecución que contra la Compañia de Jesus se lebantó en el Brasil dominio de Portugal; 4º noticias desde el año de 1755 hasta el de 1759, tanto á lo que corresponde á los negocios del Paraguay, comó a las persecuciones de los padres de la Compañia en Portugal; $5^{\circ}$, Reflexiones sobre el manifiesto de Lisboa.

- Numero 60. Un legajo sin enquadernar y sin cubierta que contiene 9 quadernos del yndice corriente de la libreria de San Lorenzo el Real del Escorial dispuesto por el padre Villegas, Bibliothecario actual sobre lo que dejo trabajado su antecesor el reverendo padre fray Antonio de San Joseph.

- Numero 61. Un legajo sin enquadernar que comprehende 4 quadernos de cartas de don Yñigo Lopez de Mendoza, marques de Santillana, y de don Alonso de Cartagena, obispo de Burgos, sobre el juramento ó sacramento militar y sus obligaciones, y asimismo otros opusculos del mismo maques hechos copiar por el padre Burriel de un manuscrito de coloquios ó dialogos de nobleza de Francisco de Quiros.

- Numero 62. Un tomo enquadernado en pergamino que contiene diferentes papeles y cartas eruditas y está rotulado por fuéra: Varios monumentos antiguos.

- Numero 63. Un tomo enquadernado en pergamino que contiene diversas cartas y escritos y está rotulado por fuera: Varias cartas de erudicion.

- Numero 64. Un legajo sin cubierta que contiene en 4 quadernos un papel intitulado: El pajaro flamenco ó phenicóptero, y conjetura si acaso el penicopero seria el primitivo Phenix; escrito por fray Martin Sarmiento, benedictino, en Madrid á 16 de enero de 1757.

- Numero 65. Un legajo sin cubierta que contiene varios quadernos de memorias para la historia de la poesia y poetas españoles por fray Martin Sarmiento, monge de San Benito en Madrid.

- Numero 66. Un legajo en $4^{\circ}$ sin cubierta que contiene 9 quadernos de Trobes de Mosem Jaume de Febrer ó Noviliario de Valencia, copiado para el padre Andres Burriel. 
- Numero 67. Un quaderno en $4^{\circ}$ que se intitula Bernardina, sive de Turcarum clase expugnata ac deleta auspiciis fortitudine et industria illustris ac incliti viri D. Bernardini de Mendoza. Hispaniae clasis ducis stremisimi, autore Joanne Vilchio Antiquario. Parece ser la $1^{\text {a }}$ copia en limpio hecha para el Yllustrisimo señor don Luis Hurtado de Mendoza, marques de Mondejar, virrey de Granada, á quien la dedicó.

- Numero 68. Un legajo sin cubierta que contiene varias cartas en folio y en $4^{\circ}$ de diferentes eruditos, algunas antiguas y otras al padre Burriel, con respuestas de éste.

$Y$ éstos 68 codices, legajos y quadernos manuscritos son los que el reverendisimo padre Diego de Rivera, rector del colegio Ymperial de la Compañia de Jesus de ésta corte ha dado a Su Magestad para su Real Bibliotheca como queda expresado al principio de ésta memoria. Y para que conste lo firmo en Madrid a $1^{\circ}$ de agosto de 1762. = Don Juan de Santander» 11.

"De estos documentos también podemos encontrar una copia, con letra más cursiva, en la Biblioteca de la Real Academia de la Historia, signatura 9/5921, folios 60r-69v (memoria) y $70 \mathrm{r}-87 \mathrm{r}$ (inventario). Es de este inventario de donde hemos transcrito el número 55, ya que en el anterior no constaba. 